\title{
Statistical optimization of alkaline protease production from newly isolated Pseudomonas species MTCC 16017
}

\author{
Swapna Vadlamani*, Rama Raju Badhe, Sreenivas Rao Parcha \\ National Institute of Technology, Warangal (AP), India. \\ Email: swapnavad2003@gmail.com
}

Received 19 December 2012; Received in revised form 22 April 2013; Accepted 25 April 2013

\begin{abstract}
Aims: The present study was investigated to optimize the production parameters using statistical method of the industrially important enzyme alkaline protease from newly isolated strain Pseudomonas putida from soil microorganisms.

Methodology and results: Among 50 isolates of extensive screening two highly productive strains were selected. One among after biochemical characterization both laboratory level and by IMTECH Chandigarh was confirmed as $P$. putida. Submerged fermentation was carried out and statistical optimization methods Plackett and Burman and RSM were used to optimize the production parameters.

Conclusion, significance and impact of study: Among the two selected strains out of 50 isolates, $P$. putida was identified as the one of the major protease producer. In this study eleven parameters were selected for the fractional factorial design (Plackett and Burman). Four significant parameters including time, carbon source, nitrogen source and salt showed significant impact on the alkaline protease production. During the study an increase in the alkaline protease activity from $4.659 \mathrm{U} / \mathrm{mL}$ to $7.396 \mathrm{U} / \mathrm{mL}$ was observed. Based on the above data more complex designs, such as Box Wilson design to study the impact of individual significant variable on the enzyme production as well as interactive effects among these significant variables were carried out. The interactive effect of the most influential parameters resulted in increase in enzyme activity from 7.246 up to $10.818 \mathrm{U} / \mathrm{mL}$ in $60 \mathrm{~h}$. Analysis of variance showed the adequacy of the model and verification experiments confirmed its validity.
\end{abstract}

Keywords: Alkaline protease, Plackett and Burman method, RSM, Pseudomonas putida

\section{INTRODUCTION}

Proteases termed as Industrial masters occupy the third largest position in enzyme production. Proteases find their applications in various industrial sectors such as in food, detergent, tannery, Photography and other industries (Kumar and Takagi, 1999; De Coninck et al., 2000; Gupta et al., 2002; Puri et al., 2002). Most of the available proteases produced commercially are of microbial origin. It is a renowned fact that environmental and nutritional factors greatly influence extracellular protease production in microorganisms. In our study we included fructose and peptone as carbon, nitrogen sources (Hanlon et al., 1982; Kole et al., 1988; Banerjee and Bhattacharya, 1993; Kumar and Takagi, 1999; Calik and Ozdamar, 2001; Chi and Zhao, 2003; Rai and Mukherjee, 2009) and environmental factors such as $\mathrm{pH}$, temperature, agitation rate and incubation time (Razak et al., 1994; Gupta et al., 2002; Puri et al., 2002) along with inoculums amount.

The classical method 'one-at-a-time-approach' is the most commonly used to optimize the production parameters to enhance the enzyme yield. This approach consumes lot of time in addition ignores the mutual interactions among various physicochemical parameters. Statistical optimization techniques such as Plackett and Burman (Plackett and Burman, 1946; Moon and Parulekar, 1993; Mekala et al., 2008; Reddy et al., 2008) and RSM (Response Surface Method) which includes factorial design and regression analysis, helps in evaluating the effective factors and building models to study interaction and select optimum conditions of variables for a desirable response (Kunamneni et al., 2005; Reddy et al., 2008). In recent times, numerous statistical experimental designs with response surface method (RSM) have been employed for optimizing enzyme production from microorganisms (Puri et al., 2002; Saran et al., 2007; Rai et al., 2009; Swapna and Sreenivas, 2011). Significant parameters for statistical optimization of protease production using locally isolated $P$. putida species their interaction effects are reported below. 


\section{MATERIALS AND METHODS}

\section{Isolation and enzyme production}

Soil samples from different regions of Andra Pradesh were collected and protease producing strains were isolated on skim milk agar. After inoculation the plates were incubated at $37{ }^{\circ} \mathrm{C}$ for $48 \mathrm{~h}$. After incubation bacterial colonies appearing over skim milk agar medium were identified based on colony characteristics and their identities were confirmed through Gram staining methods and by a series of biochemical tests as prescribed by Bergey's manual. For enzyme production, microbes were cultured in $250 \mathrm{~mL}$ of Erlenmeyer flask containing $100 \mathrm{~mL}$ culture medium, which consists of $10.0 \mathrm{~g}$ of fructose, $3.5 \mathrm{~g}$ peptone, $3.5 \mathrm{~g}$ yeast extract, $0.5 \mathrm{~g} \mathrm{~K}_{2} \mathrm{HPO}_{4}, 0.1 \mathrm{~g}$ $\mathrm{MgSO}_{4} \cdot 7 \mathrm{H}_{2} \mathrm{O}$. The inoculated medium was placed in a thermostatic orbital shaker for $48 \mathrm{~h}$ at $37^{\circ} \mathrm{C}$ and $120 \mathrm{rpm}$. The culture was centrifuged at $10,000 \mathrm{rpm}$ for $10 \mathrm{~min}$ to obtain crude enzyme in the supernatant.

\section{Assay for proteolytic activity}

Alkaline protease activity studies were done by applying a modified method given by (Gupta et al., 2002). According to this procedure $0.25 \mathrm{~mL}$ of Tris- $\mathrm{Hcl}(50 \mathrm{mM}, \mathrm{pH} 10.5)$ buffer was incubated with $2.5 \mathrm{~mL}$ of $0.6 \%$ casein dissolved in the same buffer at $30{ }^{\circ} \mathrm{C}$ until equilibrium was achieved. An aliquot of $0.25 \mathrm{~mL}$ of the enzyme solution was added to this mixture and incubated for $20 \mathrm{~min}$. The reaction was stopped by adding $2.5 \mathrm{~mL}$ TCA solution (0.11 M trichloroacetic acid). After $10 \mathrm{~min}$ the entire mixture was centrifuged at $5000 \mathrm{~g}$ for $15 \mathrm{~min}$. Supernatant in the amount of $0.5 \mathrm{~mL}$ was mixed with $2 \mathrm{~mL}$ of $0.5 \mathrm{M}$ $\mathrm{Na}_{2} \mathrm{CO}_{3}$ and $1 \mathrm{~mL}$ of Folin-Ciocalteu's phenol solution and kept for $30 \mathrm{~min}$ at room temperature. The optical densities of the solutions were determined with respect to the sample blanks at $660 \mathrm{~nm}$. For these studies, one alkaline protease unit was defined as the enzyme amount that could produce $1 \mathrm{mg}$ of tyrosine in one minute under the defined assay conditions.

\section{Statistical optimization of protease production using response surface methodology}

The alkaline protease production is influenced by various production parameters including nutritional and environmental parameters. Statistical optimization was carried out for higher enzyme production using various nutritional and environmental parameters using 'Design Expert 8.5' software. The Plackett-Burman experimental design was applied to investigate the significance of various medium components on alkaline protease production. Eleven culture variables were tested in two levels: -1 for low level and +1 for high level based on Plackett-Burman matrix design, which is a fraction of a two-level factorial design and allows the investigation of $\mathrm{n}-1$ variables in at least $\mathrm{n}$ experiments. The main effect of each variable was calculated simply as the difference between the averages of measurements made at a high setting (+1) and the average of measurements observed at a low setting $(-1)$ of that factor. The levels of these variables were optimized for enhancing the protease yield using a response surface Box-Behnken experiment design. The design matrix with $\mathrm{n}$ experimental runs in two blocks with three replicates of the midpoint. The significant variables selected for optimization, were coded as a, b, c ... respectively.

$\mathrm{Y}=\mathrm{a}_{0}+\sum \mathrm{a}_{\mathrm{i}} \mathrm{C}_{\mathrm{i}}+\sum \mathrm{a}_{\mathrm{ii}} \mathrm{C}_{\mathrm{i}}^{2}+\sum \mathrm{a}_{\mathrm{ij}} \mathrm{C}_{\mathrm{i}} \mathrm{C}_{\mathrm{j}}$

where $Y$ is the predicted response (total protease production in $\mathrm{U} / \mathrm{mL}$ ), $a_{0}$ is the intercept term, $a_{i}$ is the linear effect, $a_{i i}$ is the square effect, $a_{i j}$ is the interaction effect, and $C_{i}$ and $C_{i}$ are the variables. The above equation was used to optimize the values of independent parameters for the response. Multiple regression analysis, response surface plots and statistical analyses were performed using Design Expert Statistical Software ${ }^{\circledR}$ (Miniapolis USA).

\section{RESULTS AND DISCUSSION}

\section{Isolation of bacteria}

Bacteria producing alkaline protease were isolated from soil by serial dilution techniques. Superior microbial strain having high productivity is selected from zone of hydrolysis assay. The isolated bacteria having maximum zone of hydrolysis (Figure 1) were identified through a series of biochemical tests (Table 1) as Pseudomonas putida for further confirmation the sample was sent to IMTECH Chandigarh and the biochemical characterization results were shown in Table 1.

Table 1: Biochemical characterization results.

\begin{tabular}{ll}
\hline Biochemical Test & Pseudomonas sp. \\
\hline Catalase & Negative \\
Urease test & Negative \\
Starch hydrolysis & Positive \\
Casein hydrolysis & Positive \\
Carbohydrate & Acid \\
a) Glucose & Positive \\
b) Sucrose & Positive \\
c) Maltose & Negative \\
Gram reaction & Negative \\
Shape & Rod \\
\hline
\end{tabular}

\section{Statistical optimization of protease production using Plackett and Burman method}

The Plackett-Burman experimental design was applied to investigate the significance of various medium components on alkaline protease production. Eleven 
culture variables were tested in two levels: -1 for low level and +1 for high level based on Plackett-Burman matrix design. In this study the independent variables were screened in 12 combinations according to the matrix. Glucose, peptone, $\mathrm{KH}_{2} \mathrm{PO}_{4}$ and time were identified as significant parameters affecting alkaline protease production as indicated in (Figure 1).

\section{Response Surface Method}

The levels of the four significant variables obtained from Placket and Burman design were optimized for enhanced protease production using response surface BoxBehnken experiment design. The design matrix with 20 experimental runs in two blocks with three replicates of the midpoint is shown in (Table 2). The variables selected for optimization, i.e. glucose, $\mathrm{KH}_{2} \mathrm{PO}_{4}$, peptone concentration, and incubation time was coded as $\mathrm{A}, \mathrm{B}, \mathrm{C}$ and $D$ respectively. The goodness-of-fit of the model was checked by determining the coefficient of determination $\left(R^{2}\right)$ and adjusted $R^{2}$. When $R^{2}$ is large, then, the regression has accounted for a large proportion of the total variability in the observed value of $Y$ which favors the

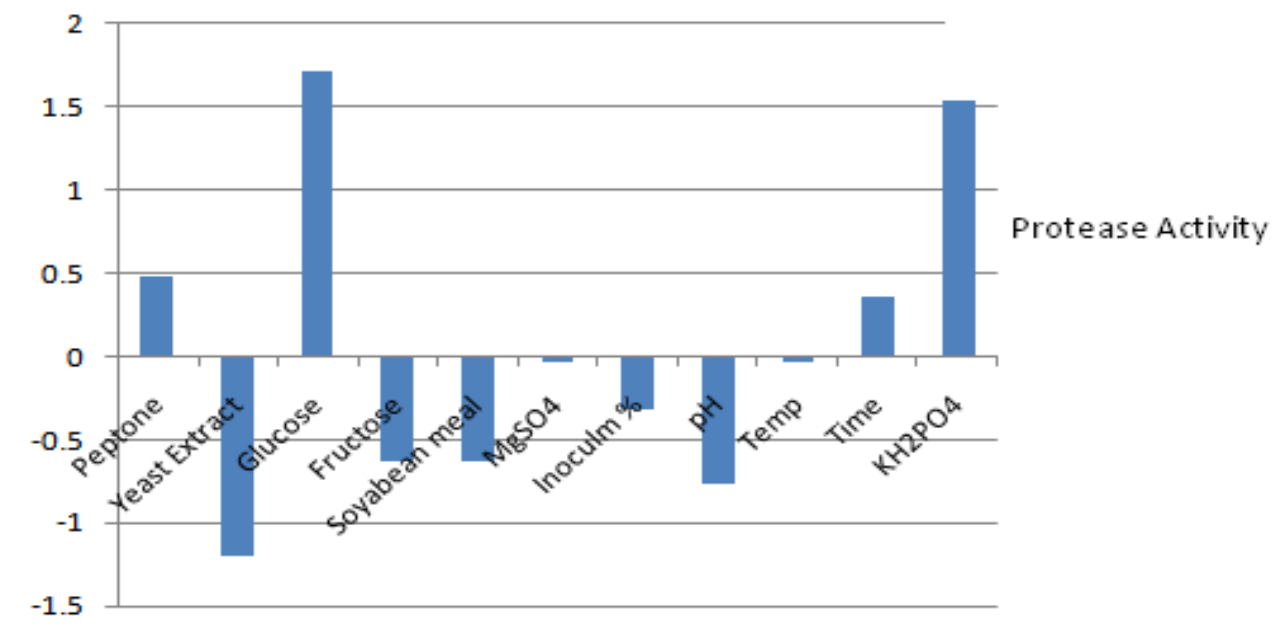

Figure 1: Significant main effects of production parameters from the Plackett-Burman design.

Table 2: Box-Behnken experiment design matrix with observed and predicted responses for different experiments.

\begin{tabular}{cccc}
\hline $\begin{array}{c}\text { Factor } \begin{array}{c}\mathrm{A}(\text { Glucose }) \\
(\mathrm{g} / \mathrm{mL})\end{array} \\
-1\end{array}$ & $\begin{array}{c}\text { Factor } \mathrm{B}\left(\mathrm{KH}_{2} \mathrm{PO}_{4}\right) \\
(\mathrm{g} / \mathrm{mL})\end{array}$ & $\begin{array}{c}\text { Factor } \mathrm{C}(\text { Peptone }) \\
(\mathrm{g} / \mathrm{mL})\end{array}$ & Factor D (Time) $(\mathrm{h})$ \\
\hline-1 & 0 & 0 & 0 \\
0 & 1 & 1 & -1 \\
0 & 0 & 0 & 1 \\
0 & 0 & 0 & 0 \\
0 & 0 & 0 & 0 \\
-1 & 0 & 0 & -1 \\
-1 & -1 & -1 & 1 \\
0 & 1 & -1 & 0 \\
0 & 0 & 1 & 0 \\
0 & 0 & 0 & 0 \\
0 & 0 & -1 & 0 \\
0 & 1 & 0 & 0 \\
1 & -1 & 0 & -1 \\
0 & 1 & 1 & 0 \\
0 & 0 & 0 & 0 \\
1 & 0 & 0 & 0 \\
1 & 0 & 0 & 1 \\
-1 & -1 & -1 & -1 \\
1 & -1 & 1 & 1 \\
1 & -1 & 1 & -1 \\
\hline
\end{tabular}


Table 3: Analysis of variance for Response Surface Quadratic model.

\begin{tabular}{lccccc}
\hline Source & $\begin{array}{c}\text { Sum of } \\
\text { squares }\end{array}$ & df & Mean square & F-value & $P$ value $>F$ \\
\hline Model & $8.157 \mathrm{E}+007$ & 10 & $8.157 \mathrm{E}+006$ & 8.29 & 0.0013 \\
A-A & 0.41 & 1 & 0.41 & $4.20701 \mathrm{E}-0$ & 0.9995 \\
B-B & 0.21 & 1 & 0.21 & $2.174 \mathrm{E}-007$ & 0.9996 \\
C-C & $9.600 \mathrm{E}+006$ & 1 & $9.600 \mathrm{E}+006$ & 9.76 & 0.0108 \\
D-D & 0.25 & 1 & 0.25 & $2.520 \mathrm{E}-007$ & 0.9996 \\
AB & $2.402 \mathrm{E}+006$ & 1 & $2.402 \mathrm{E}+006$ & 2.44 & 0.1492 \\
AC & $200 \mathrm{E}+007$ & 1 & $1.200 \mathrm{E}+007$ & 12.2 & 0.0058 \\
AD & $2.399 \mathrm{E}+006$ & 1 & $2.399 \mathrm{E}+006$ & 2.44 & 0.1494 \\
BC & $1.199 \mathrm{E}+007$ & 1 & $1.199 \mathrm{E}+007$ & 12.19 & 0.0058 \\
BD & $2.398 \mathrm{E}+006$ & 1 & $2.398 \mathrm{E}+006$ & 2.44 & 0.1495 \\
CD & $1.199 \mathrm{E}+007$ & 1 & $1.199 \mathrm{E}+007$ & 12.19 & 0.0058 \\
Residual & $9.835 \mathrm{E}+006$ & 10 & $9.835 \mathrm{E}+005$ & 8.29 & \\
Lack of fit & $9.835 \mathrm{E}+006$ & 6 & $1.639 \mathrm{E}+006$ & $1.535 \mathrm{E}+006$ & $<0.0001$ \\
Pure error & 4.27 & 4 & 1.07 & & Significant \\
Cor Total & $9.140 \mathrm{E}+007$ & 20 & & & \\
\hline
\end{tabular}

regression equation model. The observed values of $\mathrm{R}^{2}$ $(97.88 \%)$ explain that the fitted model is $97.88 \%$ of the total variation and hence vouches for adequacy of the model and only $2.12 \%$ can occur due to chance. $P$ values of each of the parameters and their quadratic and interaction terms are indicated in (Table 3). The significance of individual variables can be evaluated from their $P$ values, the more significant terms having a lower $P$ -value. The values of $P>F$ less than 0.05 indicates that the model terms are significant and this case $B, C, A B$ and $B^{2}$ were found to be significant model terms.

Response surface curves were plotted to understand the interaction effects of variables and for identifying the optimal levels of each parameter for attaining maximal protease yield. Figure $2 \mathrm{a}-2 \mathrm{f}$ represents the response surfaces obtained for the interaction effects of tested variables. The data presented in the response plots indicated that the alkaline protease production increased with an increase in the concentration of fructose up to optimum value and then started decreasing the yield this may be due to catabolic repression effect. Swapna and Sreenivasa Rao (2011) reported fructose as one of the better carbon source than glucose producing higher enzyme yields Calik, Reddy and Razak also reported positive influence of carbon source (Razak et al., 1994; Çalık and Özdamar, 2001; Reddy et al., 2008) on enzyme production up to certain extent and further increase resulted in decrease in enzyme production due to catabolic repression Gupta reported organic nitrogen source has positive influence on enzyme yield, which was also observed in our case where peptone prominently has positive influence on enzyme yield (Gupta et al., 2002). Time has profound positive influence on enzyme production and this was also reported by Puri et al., 2002. Increase in time increases the enzyme production and longer timescales decline phase appears may be due to depletion of nutrients or may be auto digestion of the enzyme (Chu et al., 1992). The optimum glucose, peptone concentration is $1.4 \mathrm{~g} / 100 \mathrm{~mL}$ and time $34 \mathrm{~h}$ for maximum

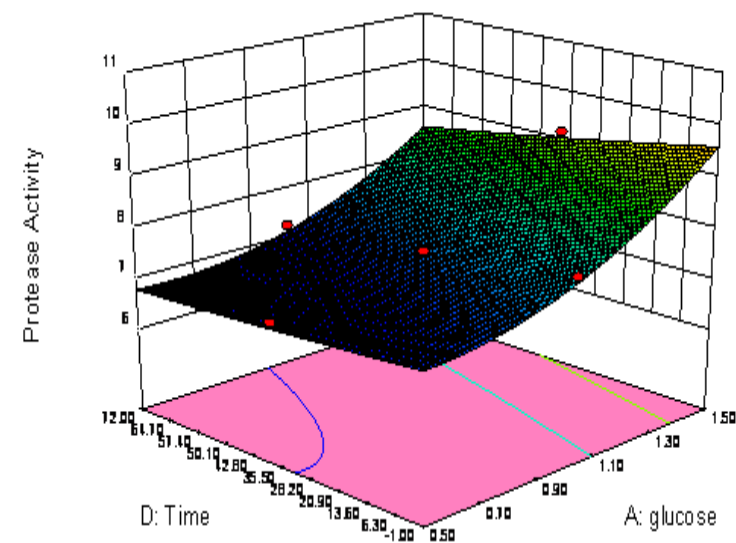

Figure 2(a): Response curve of carbohydrate and time vs protease activity.

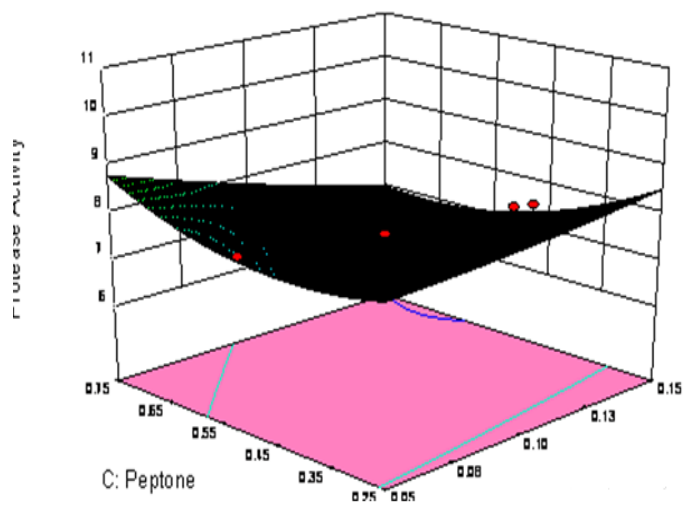

Figure 2(b): Response curve of nitrogen source and $\mathrm{KH}_{2} \mathrm{PO}_{4}$ vs protease activity. 


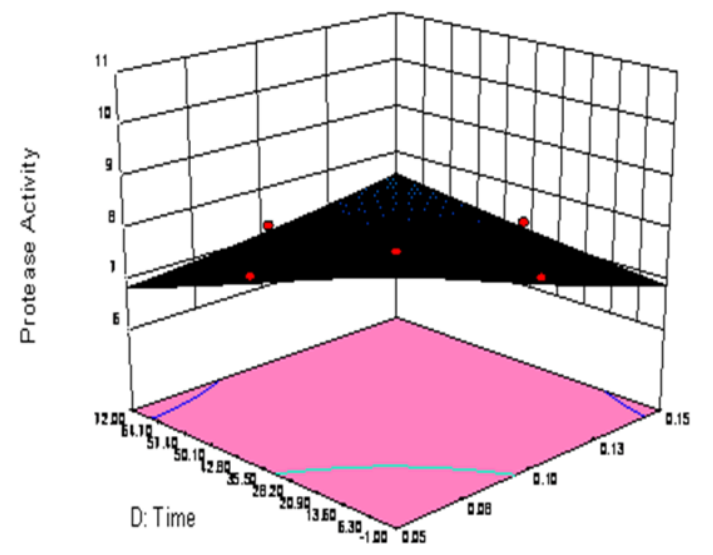

Figure 2(c): Response curve of time and $\mathrm{KH}_{2} \mathrm{PO}_{4}$ vs protease activity.

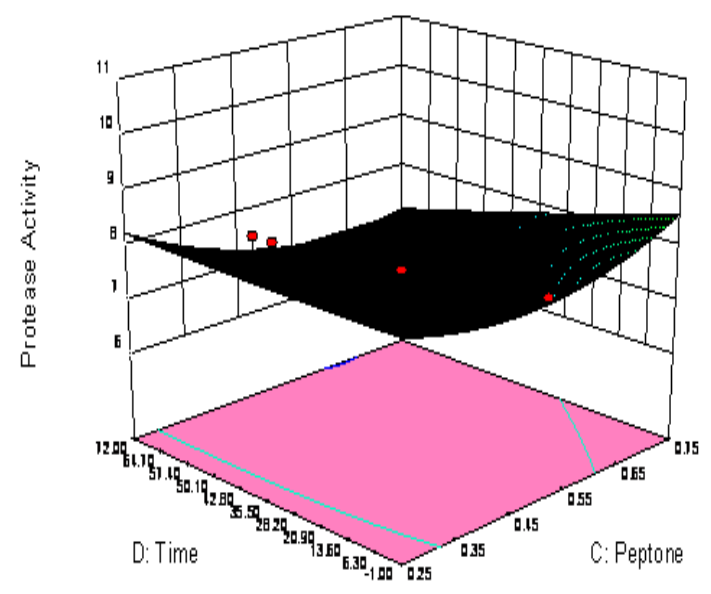

Figure 2(d): Response curve of time and carbon source vs protease activity.

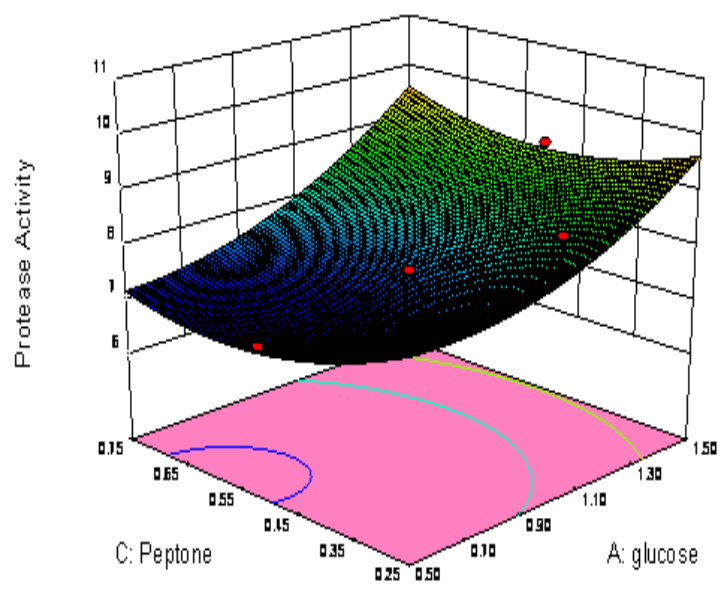

Figure 2(e): Response curve of nitrogen source and carbon source vs protease activity.

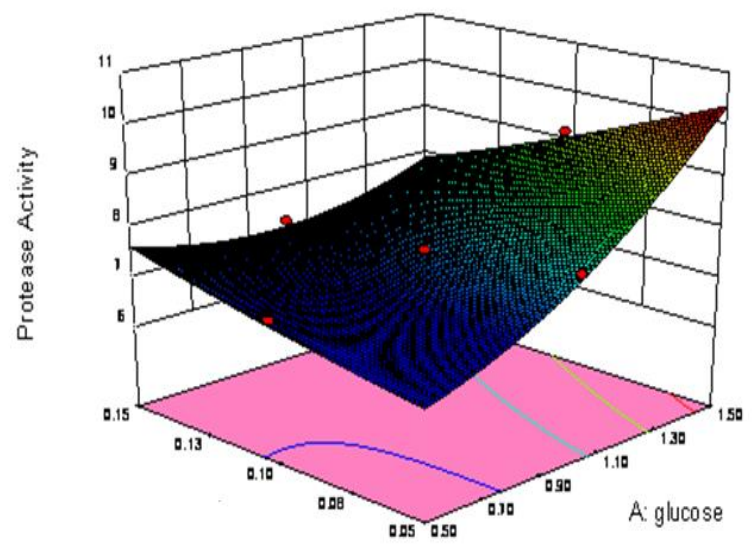

Figure 2(f): Response curve of $\mathrm{KH}_{2} \mathrm{PO}_{4}$ and carbon source vs protease activity.

yield. $\mathrm{KH}_{2} \mathrm{PO}_{4}$ concentration has significant influence on protease production and optimum value is 0.06 . Validity experiment was conducted with optimum values and similar increase in protease production of 10.898 is observed.

Recent studies were conducted on statistical optimization of different production parameters of different organisms using response surface methodology (Reddy et al., 2008; Mekala et al., 2008; Swapna and Sreenivasa Rao, 2010). Every organism is unique in its requirement, no defined media in particular and environmental parameters for maximum enzyme production as it vary for one organism to another. Therefore, each of them has to be considered separately and the requirements have to be optimized accordingly. In this study a 2.3 fold increase from $4.659 \mathrm{U} / \mathrm{mL}$ to 10.898 by optimizing production parameters time, Fructose concentration and $\mathrm{MgSO}_{4}$ concentration was observed. Recent study done by Gupta et al. (2002) on Bacillus sp. RGR-14 for alkaline protease production, reported a 12.85 fold increase by optimizing starch, phosphate ion and inoculums concentrations using the response surface method. Another study performed by Gupta et al. (2002) showed that alkaline protease production produced by Bacillus mojavensis was improved up to 4.2 fold in a bioreactor of $14 \mathrm{~L}$ using RSM.

\section{CONCLUSIONS}

Statistical optimization of production parameters considering the interactive effects of the most influential parameters resulted in overall enzyme activity from 4.659 up to $10.889 \mathrm{U} / \mathrm{mL}$ in $60 \mathrm{~h}$. A 2.33 fold increase by optimizing time, fructose concentration and $\mathrm{MgSO}_{4}$ concentration is observed. Thus a statistical approach of optimization is very much useful and less time consuming considering the interaction effects provides a basis for conduction short term experiments with better performance. 


\section{REFERENCES}

Banerjee, R. and Bhattacharyya, B. C. (1993). Kinetic properties of extracellular alkaline proteases of Rhizopus oryzae. Journal of Fermentation and Bioengineering 75, 380-382.

Çalik, P. and Özdamar, T. H. (2001). Carbon sources affect metabolic capacities of Bacillus species for the production of industrial enzymes: theoretical analyses for serine and neutral proteases and $\alpha$ amylase. Biochemical Engineering Journal 8(1), 61-81.

Chi, Z. and Zhao, S. (2003). Optimization of medium and cultivation conditions for pollen production by a new pullulan-producing yeast strain. Enzyme and Microbial Technology 33, 206-211.

Chu, I., Lee, C. and Li, T. S. (1992). Production and degradation of alkaline protease in batch cultures of Bacillus subtilis ATCC 14416. Enzyme and Microbial Technology 14 (9), 755-761.

De Coninck, J., Bouquelet, S., Dumortier, V., Duyme, F. and Verdier-Denantes, I. (2000). Industrial media and fermentation processes for improved growth and protease production by Tetrahymena thermophila BIII. Journal of Industrial Microbiology and Biotechnology 24 (4), 285-290.

Gupta R., Beg, Q. and Lorenz, P. (2002). Bacterial alkaline proteases: Molecular approaches and industrial applications. Applied Microbiology and Biotechnology 59(1), 15-32.

Hanlon, G. W., Hodges, N. A. and Russell, A. D. (1982). The influence of glucose, ammonium and magnesium availability on the production of protease and bacitracin by Bacillus licheniformis. Journal of General Microbiology 128(4), 845-851.

Kole, M. M., Draper, I. and Gerson, D. F. (1988). Production of protease by Bacillus subtilis using simultaneous control of glucose and ammonium concentrations. Journal of Chemical Technology and Biotechnology 41(3), 197-206.

Kumar, C. G. and Takagi, H. (1999). Microbial alkaline proteases: From a bioindustrial viewpoint. Biotechnology Advances 17(7), 561-594.

Kunamneni, A., Kumar, K. S. and Singh, S. (2005). Response surface methodology approach to optimize the nutritional parameters for enhances aamylase. African Journal of Biotechnology 4, 708716.
Mekala, N. K., Singhania, R. R., Sukumaran, R. K. and Pandey, A. (2008). Cellulase production under solid-state fermentation by Trichoderma reesei RUT C30: Statistical optimization of process parameters. Applied Biochemistry and Biotechnology 151(2-3), 122-131.

Moon, S. H. and Parulekar, S. J. (1993). Some observations on protease production in continuous suspension cultures of Bacillus firmus. Biotechnology and Bioengineering 41(1), 43-54.

Plackett, R. L. and Burman, J. P. (1946) The design of optimum multifactorial experiments. Biometrika 33, 305-325.

Puri, S., Beg, Q. K. and Gupta, R. (2002). Optimization of alkaline protease production from Bacillus sp. by response surface methodology. Current Microbiology 44(4), 286-290.

Rai, S. K. and Mukherjee, A. K. (2009). Ecological significance and some biotechnological application of an organic solvent stable alkaline serine protease from Bacillus subtilis strain DM04. Bioresource Technology 100(9), 2642-2645.

Razak, N. A., Samad, M. Y. A., Basri, M., Yunus, W. M. Z. W., Ampon, K. and Salleh, A. B. (1994). Thermostable extracellular protease of Bacillus stearothermophilus: Factors affecting its production. World Journal of Microbiology and Biotechnology 10(3), 260-263.

Reddy, L. V. A., Wee, Y. J., Yun, J. S. and Ryu, H. W. (2008). Optimization of alkaline protease by batch culture of Bacillus sp. RKY3 through PlacketBurman and response surface methodological approaches. Bioresource Technology 99, 22422249.

Saran, S., Isar, J. and Saxena, S. J., (2007). Statistical optimization of conditions for protease production from Bacillus sp. and its scale-up in a bioreactor, Applied Biochemistry and Biotechnology 141, 229239.

Swapna, V. and Sreenivasa Rao, P. (2011). Studies on Industrially Important alkaline protease production from locally isolated superior microbial strain from soil microorganisms. International Journal of Biotechnology Applications 3(3), 102-105. 